\title{
STOP AND SEARCH: DISPROPORTIONALITY, DISCRETION AND GENERALISATIONS
}

It has long been recognised that discretion is vital to good police work. However, in Britain (and many other countries), practices of discretion in the stop and search context have come under much scrutiny as it has widely been linked to racist practices, i.e. a disproportionate amount of Black and minority ethnic individuals are stopped and searched compared to White people. In a bid to counteract the discretionary practices that are seen to be linked to racist stops and searches, police officers are required (in stops and searches under section 1 of the PACE code A) to have 'reasonable grounds for suspicion'. This article evaluates what has been claimed as the tension between the required reasonable grounds for suspicion and the need to draw on generalisations (police discretion) for effective policing.

Keywords: discretion; intuition; reasonable suspicion; stop and search; suspicion

\section{Introduction}

It has long been recognised that discretion is vital to good police work (see Kleinig, 1996; Walker, 1993). However, in Britain (and many other countries), practices of discretion in the stop and search context have come under much scrutiny as it has widely been linked to racist practices, i.e. a disproportionate amount of Black and minority ethnic individuals are stopped and searched compared with White people. In a bid to counteract the discretionary practices that are seen to be linked to racist stops and searches, police officers are required (in stops and searches under s 1 of the PACE Code A) to have 'reasonable grounds for suspicion' (Home Office, 2005: [1.4 $]^{1}$ ). This article evaluates what has been claimed as the tension between the required reasonable grounds for suspicion and the need to draw on generalisations (police discretion) for effective policing (Quinton et al., 2000).

After discussing some of the criticisms of PACE Code A related to the problems of disproportionality, discretion and 
generalisations, the article looks at evidence from research conducted in the neurosciences which concludes that intuitive decision-making processes (allied to generalisations) are often fundamental to the formation of reasoned judgements. The article then argues that distinctions between generalisations and grounded forms of reasoning are often falsely dichotomised and thus lead to practices likely to affect vital policing skills negatively in the stop and search context. Instead of rooting out racism, PACE code $\mathrm{A}$ has tended to shift the focus to rooting out subjectivity (for example the development of personalised policing expertise), which is argued as being at the heart of much good policing work.

\section{Background}

The Home Office states that '[S]top and search powers allow the police to combat street-crime and anti-social behaviour, and prevent more serious crime'. ${ }^{2}$ The primary purpose of this police power is 'to enable officers to allay or confirm suspicions about individuals without exercising their power of arrest' (PACE, Code A [1.4]). They are seen as a means to:

- Prevent crime occurring in the first place

- Detect crime when it has been committed

- Make communities safer

- Increase public confidence and trust in their local police service

- Provide the police with intelligence to help tackle local problems. ${ }^{3}$

Although both the police and a high proportion of the public believe that stop and search police powers are a valuable tactic to use against criminals (ACPO, 2005), it remains today one of the most contentious aspects of British policing. Numerous individual experiences, reports, statistics and research suggest that there is an unsettling level of ethnic disproportionality; that is, particular ethnic groups are seen as being targeted by the police across Britain through the stop and search powers.

There is a range of legislation which gives police officers the power to stop and search; for example: s 1 of the Police and Criminal Evidence Act 1984 (PACE); s 60 of the Criminal Justice and Public Order Act 1994; and s 44 of the Terrorism Act 2000. This article is concerned with only s 1 of PACE Code A because the present author's particular focus is the notion of 'reasonable grounds for suspicion' and its continued relationship with the problem of disproportionality. Section 1 of PACE Code 
A empowers 'an officer who has reasonable grounds for suspicion to stop and search a person or vehicle to look for stolen or prohibited items' (Ministry of Justice, 2009). Most of the stops and searches in England and Wales are conducted under s 1 of PACE Code A; for example, in 2007/08 recorded stop and searches under the section in England and Wales made up almost $86 \%$ of all stop and searches and there were:

- $1,035,438$ s 1 stop and searches in $2007 / 8$

- 53,125 s 60 stop and searches in $2007 / 8$

- 117,278 s 44 stop and searches in 2007/8. (Ministry of Justice, 2009)

The Office for National Statistics estimated that the population for England and Wales in 2008 was somewhere in the region of $54,440,000 .{ }^{4}$ These figures suggest a little less than $2 \%$ of the general population of England and Wales underwent a $\mathrm{s} 1$ recorded stop and search in 2007/8. This figure may not be too much cause for alarm, but it is not until we look at the percentage of stops and searches by 'ethnic appearance' that alarm bells ring. For every 1,000 White people in England and Wales in 2007/8, 17 were stopped and searched, compared with 40 for Asian people and a staggering 129 for Black people. That is, $12.9 \%$ of the Black population in England and Wales were stopped and searched in 2007/8 compared with $1.7 \%$ of the White population (Ministry of Justice, 2009). ${ }^{5}$ The general amount of s 1 recorded stops and searches has steadily increased since s 95 of the Criminal Justice Act required police to start recording stop and search phenomena. For example, in 2004/5 there were 840,000 stop and searches recorded in England and Wales, in 2006/7 there were 955,113, but the increase for White people from $2006 / 7$ to $2007 / 8$ was $7 \%$, for Black people $13 \%$ and for Asian people $16 \%$. All of these figures clearly suggest that, far from a decrease in disproportionality in ethnic stop and search patterns, there is a continued increase. What should be done? Bowling and Phillips argue that '[I]f stop and search powers cannot be effectively regulated - and it seems that they cannot - then their continued use is unjustified and should be curtailed' (Bowling \& Phillips, 2002: 1), and this is a point which often re-emerges (e.g. see Walker \& Starmer, 1993). However, as cited above, proponents for stop and search continue to argue that the interference caused to liberties are outweighed as it has now become a vital police activity in keeping communities safe in that they are effective in disrupting 
crimes before and when committed (Lerner, 2006), and the practice visibly reassures the public (Reid, 2009).

Since the Brixton, Toxteth and St Pauls riots in the 1980s a subsequent report (Scarman, 1981) known as the Scarman Report pointed out a number of deficiencies with stop and search practices, particularly with regard to racial discrimination. The report recommended new training procedures and new procedures objectively to govern stop and search practices (see Bowling \& Phillips, 2002). ${ }^{6}$ In 1986, PACE (the Police and Criminal Evidence Act 1984) was introduced to promote safeguards against police discriminatory practices by structuring police discretion, principally embodied in the requirement for an officer to have 'reasonable grounds for suspicion' before a stop and search could be conducted. There have been numerous published documents recounting the history of the development of stop and search legislation and reforms (e.g. see Delsol \& Shiner, 2006; Reid, 2009; Sanders \& Young, 2007; Qureshi et al., 2006), so this section of the article will focus on issues directly concerned with s 1 of PACE's 'reasonable grounds for suspicion' in the stop and search context.

Section 1 of PACE 1984 was criticised in a number of ways; for example, for failing to regulate the discretionary practices of police officers, for the lack of consideration for informal working practices during street-level policing and for the lack of clarity regarding the criteria for reasonable suspicion (Dixon et al., 1989; McConville et al., 1991). A later report in 1999 by the Metropolitan Police Services (Fitzgerald, 1999) added that guidelines underlying stops and searches under the criterion of reasonable suspicion are highly vague and require interpretation by officers as they simply cannot cover every eventuality; hence officers revert to discretionary practices.

In 1999 the Stephen Lawrence Inquiry (Macpherson, 1999, the Macpherson Report), famously suggested that the Metropolitan Police Force was still institutionally racist and that the disproportionality in police stop and search is the result of police targeting minority groups. This led to a number of reports; for example, Her Majesty's Inspectorate of Constabulary report (HMIC, 2000) again raised the questions concerning understandings of reasonable suspicion, '[I]t is the officer alone who determines, at street level, reasonable suspicion which is a concept that has eluded academics and lawyers in more reflective surroundings' (54). It went on to recommend that 'Her Majesty's Inspector therefore recommends that independent research is commissioned to investigate; what are the prevailing conditions 
in officers' minds that leads to a "reasonable suspicion"" (54). Thus the Home Office conducted a study in which over 100 police officers were interviewed and 340 hours of observation data were collected from officers on patrol duty (Quinton et al., 2000). The following factors were outlined as central to the arousal of an officer's suspicion: appearance, behaviour, time and place, and information and intelligence. These factors were described as being too broad in that police officers, in practice, continue to rely on generalisations to form suspicions. This was seen as posing risks to public confidence. Therefore it suggested there was a 'need to improve the reliability of information on which decisions to stop or search are based' (Quinton et al., 2000: vi)

Generalisations are described as 'broad understandings that officers have about people, places, or situations that are more likely to be associated with offending' (Quinton et al., 2000: 35). However, the authors identify a tension, through the use of generalisations to form suspicions, between:

- the need to draw on generalisations for effective targeting of police activity; and

- the alienation that generalisations, potentially, and negative stereotypes, in particular, cause. (Quinton et al., 2000: 62)

Therefore the report recommends that

[T] he legal concept of reasonable suspicion and its application needs to be further clarified to specify whether current officer practices are acceptable. Although the PACE Code clearly states that stereotyped images should not be used as a basis for suspicion, we have shown that generalisations are used by officers, in practice, as a basis for suspicions. As a result, the PACE Code needs to spell out whether, and to what extent, generalisations can be used to inform decisions to stop or search. This is not to say that the law should be relaxed, but that further clarification is required. If, however, generalisations are recognised as an acceptable practice, adequate safeguards need to be in place to ensure that they are reliable and not used unfairly. (Quinton et al., 2000: 65)

Five years after this report, a stop and search manual was designed by the Home Office in 2005 by the Stop and Search 
Action Team (SSAT), 'to offer practical guidance and sound advice for police and police authorities' (Home Office, 2005: 5). The manual draws out what it sees as the 'key points' of PACE code's definition of reasonable suspicion. It stipulates that searches, 'must have an objective basis in fact, information, and/ or intelligence', then goes on to state that 'it can be based on some level of generalisation stemming from behaviour of a person in a particular situation' (Home Office, 2005: 17).

Research, however, demonstrates that, as a category, generalisations stemming from behaviour are very open especially to abuse. For example, Willis (1983) analysed details from recorded stops in stop books, stop slips, arrest sheets, charge sheets and complaints records, and also interviewed officers about how the stop powers were used. The most common reason for the stops (over 50\%) in the stop books were described as 'removements'. Further information concerning the stops could rarely be obtained from the records. When the officers were asked in the interviews to give details as to what this category covered, all gave different interpretations as to what it meant and it was concluded by Willis that 'this category covered stops made on grounds which police officers find it hard to specify'. The stops appeared to be occurring on the basis of intuitive forms of suspicion (or what may be described as generalisations) rather than on the basis of objective, reasoned grounds.

Similarly McConville, Leng and Sanders (1991) suggest that many of the stop reports are constructed through 'creative accounting' after the event of an arrest. As one officer in a study put it, he would 'stop a suspect instinctively and then think about how he would satisfy a disinterested third party' (McConville et al., 1991, cited in Maguire et al., 2007: 958). Decisions to stop and search are often described as a matter of intuition, something indefinable (McConville et al., 1991; McAra \& McVie, 2005). Similarly, in the American context, Lerner states that the legal system

forces police officers to prune what they say at suppression hearing, but it does little to change how they act on the streets of America. Months will pass before a suppression hearing, and by then it will be a simple matter to reverseengineer the objective 'reasons' for the stops. The legal system in practice rewards those officers who are able and willing to spin their behaviour in a way that satisfies judges, while it penalises other officers who are less verbally facile or who are transparent about their motivations.... Police 
officers insist that their hunches about criminals are often right and that their 'sixth sense' proves invaluable in the field. Nevertheless, when police officers testify during a suppression hearing, they almost never use the word 'hunch' or any of its variants ('sixth sense', 'gut instinct,' etc.); the entire language of intuitive thinking is excised from their vocabulary the moment they assume their place in the witness stand. Instead they seek to curry favour with judges at suppression hearings by speaking a carefully pruned discourse, which emphasizes 'objective' criteria that judges have certified in past cases. (Lerner 2006: 405-73)

Further support for this form of creative accounting comes from Gergen (1994), who reanalysed a study by Bennett and Feldman (1981) in which research participants were exposed to 47 testimonies that were either genuine attempts to recount the past or fabricated stories. The stories that were judged to be true were primarily those conforming to what are discussed as the rules of narrative and not those that were genuine. Gergen concludes that cultural expectations are placed upon the individual to tell a certain kind of story in a particular way in order for it to be believable. These types of stories tend to display a high amount of cognitive mechanistic words and are coherently structured rather than emotional and incoherent. Howard, Tuffin and Stephens (2000: 295-314) also found that police officers in New Zealand utilised what was described as a discourse of 'unspeakability' with respect to emotions, which were typically 'framed as dangerous and threatening to performance, demanding management and control' and this in turn 'enabled officers to present themselves as both culturally and professionally competent'.

\section{Intuitive Suspicion}

Police officers' need for reasonable grounds for suspicion has, it appears, led many officers to creatively construct accounts of the stops and searches. These accounts tend to downplay intuitive, emotional-feeling-affective-based insights in order for them to appear to be grounded in objective reasoning. This form of dichotomisation is discursively drawn from a large historic body of literature concerning the primacy of decision-making processes. It is either argued that they emerge, as Immanuel Kant suggested, in abstract cognitive faculties or, as David Hume suggested, within the passions. Goodenough and Prehn (2006) state that these debates perennially emerge in various contexts; for example as Intuition versus reason in the law (see Austin, 
1832, repr. 1995; Holmes, 1881; Kelson, trans. Deuticke, 1992; Goodenough, 1997; Gruter, 1992; Hart, 1961; Weinreb, 1987). The study of moral reasoning and the human capacity for normative judgements typically draw on cognitive developmental approaches advocated by Jean Piaget (1965) and Lawrence Kohlberg (1969), who in turn draw on the Kantian tradition, favouring conscious reasoning over less conscious affective processes.

We also see similar kinds of distinctions in much of cognitive psychology's research into stereotyping. Historically stereotypes have been viewed as necessarily deficient, subjective and irrational forms of processing and therefore distinct from socalled normal processing. They are often seen as tending to form the basis for negative, hostile, exploitative and unjust judgements. Zawadzki (1942: 140) stated that intellectually they are 'a very poor device in thinking' and so do not constitute good forms of knowledge. This coincides with Allport's famous definition of a stereotype as 'an exaggerated belief associated with a category [whose] function is to justify (rationalize) our conduct in relation to that category' (Allport, 1954: 191). Wegener, Clark and Petty (2006) note that contemporary stereotyping research, particularly in the field of social cognitive psychology, has tended to be led by a distinction between automatic and controlled processes, otherwise known as 'dual process models'. Automatic processes are conceptualised as requiring little to no intention and thought, hence individuals have little control over these (Bargh, 1994) through which stereotyping thrives, which in turn influences perception and judgement (Banaji \& Hardin, 1996; Devine, 1989; Perdue \& Gurtman, 1990). Controlled processes, in contrast, are thought of as being the means through which stereotypes are resisted and avoided (Devine, 1989; Devine \& Monteith, 1999; Macrae et al., 1994). Thus automatic processes are seen as drawing on stereotypes as heuristics which facilitate short cuts to judgement utilising only rudimentary cognitive skills (Macrae et al., 1994). This occurs, for example, when individuals lack: ability (due to cognitive loading), time, motivation to think more extensively (Bodenhausen et al., 1994) and accountability (Nelson et al., 1996; Neuberg, 1989). This body of research easily leads to the assumption that intuitive forms of suspicion can be allied to automatic processing while reasonably grounded forms of suspicion can be allied to controlled processes. Obviously the latter would be favoured as it appears to reduce stereotyping and hence reduce racist forms of police decision making. 
Yet more recent studies by Damasio with colleagues (Benchara et al., 2000) demonstrate ways in which nonconscious (automatic) forms of processing are at the heart of the development of decision-making processes which are related to, and arguably may be considered as, the reasonable grounds for suspicion. They looked at the autonomic nervous system arousal of participants trying to win money in a card gambling task. There were three groups of participants: a normal group and two brain lesion groups (one group consisted of participants with bilateral lesions to the ventromedial (VM) sector of the prefrontal lobe and the other group consisted of participants with bilateral amygdala lesions). Those who tended to win more money (developed appropriate gambling strategies) were the normal group of participants. Throughout the tasks skin conductance reactivity (SCR) was measured. The normal group produced increases in SCR in response to rewards and punishments that resulted through gambling decisions. As they became more experienced in the game they started to produce increases in SCR prior to gambling decisions (anticipatory responses). The increases in SCR were significantly increased for the normal group prior to making a risky gamble compared with a less risky gamble. The VM group also produced increased SCR in response to rewards and punishments; however, these were lower responses compared to the normal group and they did not produce anticipatory SCR increases. The amygdala group neither had SCR increases due to rewards and punishments nor anticipatory SCR increases. Hence the normal group all developed appropriate gambling strategies which enabled them to win money while the lesion groups did not win money. Throughout the task the participants were asked to declare whatever they knew about the task on four occasions. Damasio distinguishes four sequential levels of knowledge that the participants declared.

The first was a 'pre-punishment' period, when subjects sampled the decks before they had yet encountered any punishment. The second was a 'pre-hunch' period, when subjects began to encounter punishment but still had no clue about what was going on in the game. The third was a 'hunch' period, when subjects began to express a hunch about which decks were riskier but they were not certain. The fourth was a 'conceptual' period, when subjects knew very well that there were good and bad decks and which decks were good and bad. (Benchara \& Damasio, 2005) 
They correlated the SCR for each period and found that for the normal participants there was no significant SCR activity during the pre-punishment stage. At the pre-hunch stage there was a significant increase in SCR activity due to anticipatory responses, which is before any conscious knowledge had developed, and the SCR activity was sustained for the remaining period of the task. Of the normal participants in Benchara and Damasio's study, 30\% were not able to communicate how they developed winning strategies. Damasio therefore argues (Tranel \& Damasio, 1991: 217-29; Damasio, 1994) that gambling decisions were made through an affective autonomic biasing system: we might say the gambler felt suspicious before going on to formulate what may be considered any conscious reasoned decisions. Thus the reasoned world was born of the felt world. Damasio and colleagues nominate this autonomic biasing system the 'somatic marker hypothesis' and distinguish neural pathways involved in these processes. Somatic markers are non-conscious bodily responses to stimuli which in turn influence decision making; we might otherwise think of them as 'intuitions' or 'gutfeelings'. More support for this autonomic biasing system comes from another experiment that replicated the above gambling study but this time included only normal participants (Carter \& Pasqualini, 2004). It was found that the participants who had higher anticipatory SCR activity tended to develop the best gambling strategies. This then would seem to suggest that heightened non-linguistic activity was of primary importance to correct decision-making processes. Of interest here is that winning strategies were formed through the development of somatic markers which in turn were instituted through repeated experiences. The repeated experiences form patterns or what are considered as 'generalisations' or perhaps even 'stereotypes'.

Lerner forcefully argues that in the context of America the creation of false dichotomies of what is reasonable and unreasonable suspicion-related decision-making processes are leading to significant flaws and compromises in police activity. He argues that the term 'reasonable suspicion' has left many experienced police officers hamstrung as intuition and extra-discursive knowledge gained through years of policing experience is very much disregarded through the introduction of what is known as the 'Terry laws' (similar to PACE Code A) in America. Lerner states that the 'dichotomy between facts and intuitions is built on sand'; emotions and intuitions are not contrary or 'obstacles to reason' but can be seen as 'indispensable heuristic devices that allow people to process diffuse, complex information about their 
environment and make sense of the world' (Lerner, 2006: 405). Lerner suggests that 'hunches' or what may be considered as 'intuitions' and 'gut-feelings' are often a form of thinking that may be difficult to be persuasively conveyed in words. This does not mean that they are inferior to verbalised suspicions but may draw on a vast recollection of previous experience that may be too complex to convey in words. A skilled and experienced craftsperson often responds to problems without words. Lerner argues that the more we become an expert at a task, the more our knowledge becomes tacit or incommunicable. This is reflected in Polanyi's (1983) arguments that 'experts do not resort to first principles and consciously work through a series of logical steps, rather they rely on their experience and instinct; they have a sense of what feels right and what feels wrong' (cited in Lerner, 2006: 407). Thus Lerner argues that the legal rules governing police conduct are based upon mistaken assumptions about human cognition.

In a British study completed by Jordan (2000) one of the papers focused, among other aspects, on fairness in the application of the police stop and search act, particularly 'officer judgement' within the stop and search context. Jordan begins this part of the paper by attempting to further understand 'reasonable suspicion', which is cited as a 'nebulous concept' (2000: 23). Jordan argues it is widely accepted that officers exercise a degree of judgement as to whether something they see on the street requires intervention. However, what is less readily accepted is that police have to rely on their own 'stereotypes'; this is particularly so when 'rapid decision' making is called for. Jordan argues that the word 'stereotype' here does not necessarily connote unsophisticated and insensitive automated responses but 'is another way of saying that they are drawing upon their experience, and (inevitably) cultural influences, to summarise information about possible courses of action prior to selecting one and acting upon it' (2000: 24).

Damasio's 'somatic marker hypothesis' is of benefit here in helping us to understand these sorts of intuitive processes. He supplies evidence which suggests that there is a constant mapping within certain parts of the brain of the bio-regulatory state of the body; this is coupled with the monitoring of the external world. When stimuli are encountered, maps previously held in the neural system associated with the stimuli are rapidly reconstituted. In this way the feelings associated with the previously experienced stimuli are re-evoked. These feelings then act as a covert biasing system which facilitates rapid decision making, 
marking options with valences according to associated feelings of previous related experiences. This does not mean that decision-making behaviour is deterministic but that somatic markers facilitate processes by rapidly influencing decisions (we can either act or not act on the basis of what our feelings are suggesting). Of course, racist police officers are likely to have somatic markers that influence racist forms of decision-making processes, as they are likely to have developed particular types of maps/feelings for particular ethnic groups. The fault here, however, lies with the racist police officer and not with the intuitive processes through which decisions to stop and search are made. As has been argued, there is always going to be room for discretionary practices in the stop and search context; previous approaches of ratcheting up the need for officers to account for their stops and searches on so-called reasonable grounds are likely to simply make more officers better at 'creatively accounting' for their actions, whether they are racist or not.

\section{Conclusions}

What appears to have occurred through the introduction of the concept of 'reasonable suspicion' into the stop and search context is a shift of focus from rooting out racism to rooting out subjectivity. This is both impossible, as decision-making processes cannot be divorced from subjectivity, and simply futile, as subjectivity (for example the development of personalised policing expertise) is at the heart of much good policing work. The distinctions between suspicions being based on subjective generalisations or objective grounds appear to be in many instances posited within a play of semantics rather than an in-depth understanding of decision-making processes. The faulty logic seems to lie within an understanding that generalisations lead to stereotyping which in turn leads to racism. Pickering (1995) describes what he sees as an 'abiding problem in stereotyping research', which was initially formulated in Lippmann (1965 [1922]), credited with introducing the word 'stereotype' into the social sciences. Pickering suggests that Lippmann conceptualised the stereotype in the following opposed ways:

A Inadequate and biased, as endorsing the interests of those who use them, as obstacles to rational assessment, and as resistant to social change.

...

B A necessary mode of processing information, especially in highly differentiated societies, an inescapable way of creat- 
ing order out of 'the great blooming, buzzing confusion of reality'. Here it is equated with broader patterns of typifying and representing, and indeed with our general means of thinking and making sense of the world. (Pickering, 1995: 693)

Pickering (2001) argues that conceptualisation (B) incorrectly assumes the word 'stereotype' is a synonym with the word 'category'. In contrast to stereotypes, categories are seen as flexible and unfixed while stereotyping attempts to deny any flexible thinking 'in the interest of the structures of powers which it upholds'. He writes:

Thinking in relation to categories is a necessary way of organising the world in our minds, creating mental maps for working out how we view the world and negotiating our way through it in our everyday social relations and interactions. It would be difficult to imagine how the world would seem without using categories in general speech and writing as basic tools for organising our understanding. (Pickering, 2001: 3)

Although stereotyping has many overlaps with the above conception of thinking in relation to categories, clearly stereotyping which forms prejudices and in turn influences discriminations against particular races and ethnicities are the type of processes which the police should be focused on rooting out. Yet misconceptions concerning false dichotomies between, for example, cognition/emotion, automatic/controlled, suspicion/reason have led to the development of practices that do little actually to reduce racism in the stop and search context. It seems that effective policing skills are being discredited through faulty understandings of the processes involved in the development of suspicion. Too much emphasis on the need for reasonable grounds for suspicion does not address the underlying problems which lead to racist policing. Jordan states that '[S]ocial identity stereotypes will derive from the shared experience of other officers; messages picked up through general life experience; and from the media' and adds: '[L]ittle is known about how officers integrate and use this material' (2000: 24). Although Jordan states that it is hoped officers' 'templates', which influence stop and search decisions, are formed in the main through the patterns of intelligence that an officer receives, but of concern here is that stereotyping may open the way for forms of licensed prejudice. 
Jordan then recommends that officers learn 'to separate out the components of and influences upon those stereotypes and help officers to develop the "right" templates' (2000: 24). To this end Jordan recommends the use of Personal Construct Psychology (PCP) to facilitate police officers' better understanding of their subjectivity when undertaking decisions to stop and search. This certainly appears to be a step in the right direction, yet there are a number of relevant critiques of Kelly's PCP that state it insufficiently addresses issues concerned with language, communication, ideology and power issues (e.g., see Solas, 1992; Balnaves \& Caputi, 1993), which are arguably at the heart of racist police activity. It seems that resources could be more profitably spent by governing bodies investing in researching psychosocial factors that influence subjectivity and hence decision-making processes to further develop training and practices which aim more accurately at reducing prejudiced policing.

\section{Notes}

1 Hereafter referred to as 'Pace Code A' at [1.4].

2 See <http://www.homeoffice.gov.uk/police/powers/stop-and-search/>.

3 See <http://www.wiltshire.police.uk/index.php?option=com_content \&view=article\&catid=130:stop-and-search\&id=903: why-is-stop-andsearch-necessary \&Itemid $=41>$.

4 See $<$ http//www.statistics.gov.uk/pdfdi2r/pop0809.pdf $>$.

5 The Ministry of Justice states that '[C]aution should be exercised when using these per 1,000 population figures as they rely on estimates of the BME population based on the ethnicity breakdown of the population from the 2001 Census. As such, minority ethnic populations may be under (or over) estimated'. For further analyses of UK stop and search figures see Bowling and Phillips, 2007; and Waddington et al., 2004.

6 The Brixton riots were seen to be the result of Operation Swamp, which led to 118 arrests (12.5\% arrests per stop); a disproportionate amount of the stops were Black people.

\section{References}

Allport, G.W. (1954) The Nature of Prejudice. Cambridge, MA: Addison Wesley, 191.

Association of Chief Police Officers (ACPO) (2005) Stop and Search Manual. London: Home Office.

Austin, J. (1832) The Province of Jurisprudence Determined, 5th edn, 1885, repr. 1995. Cambridge University Press.

Balnaves, M. and Caputi, P. (1993) 'Corporate Constructs: To What Extent Are Personal Constructs Personal?' International Journal of Personal Construct Psychology 6: 119-38. 
Banaji, M.R. and Hardin, C.D. (1996) 'Automatic Stereotyping' Psychological Science 7: 136-41.

Bargh, J.A. (1994) 'The Four Horsemen of Automaticity: Awareness, Intention, Efficiency, and Control in Social Cognition', in R.S. Wyer, Jr and T.K. Srull (eds), Handbook of Social Cognition (2nd edn). Hillsdale, NJ: Erlbaum, vol. 1, 1-40.

Benchara, A., Damasio, H. and Damasio, A.R. (2000) 'Emotion, Decision Making and the Orbitofrontal Cortex' Cerebral Cortex 10(3): 295-307.

Benchara, A. and Damasio, A.R. (2005) 'The Somatic Marker Hypothesis: A Neural Theory of Economic Decision' Games and Economic Behavior 52: 336-72.

Bennett, W.I. and Feldman, M.S. (1981) Reconstructing Reality in the Courtroom: Justice and Judgment in American Culture. New Brunswick, NJ: Rutgers University Press.

Bodenhausen, G.V., Sheppard, L.A. and Kramer, G.P. (1994) 'Negative Affect and Social Judgment: The Differential Impact of Anger and Sadness' European Journal of Social Psychology 24: 45-62.

Bowling, B. and Phillips, C. (2002) Racism, Crime and Justice. London: Longman.

Bowling, B. and Phillips C. (2007) 'Disproportionate and Discriminatory: Reviewing the Evidence on Police Stop and Search' The Modern Law Review 70(6): 936-61.

Carter, S. and Pasqualini, M.C. (2004) 'Stronger Autonomic Response Accompanies Better Learning: A Test of Damasio's Somatic Marker Hypothesis' Cognition and Emotion 18(7): 901-11.

Damasio, A.R. (1994) Descartes' Error: Emotion, Reason, and the Human Brain. New York: Grosset/Putnam.

Delsol, R. and Shiner, M. (2006) 'Regulating Stop and Search: A Challenge for Police and Community Relations in England and Wales' Critical Criminology 14: 241-63.

Devine, P.G. (1989) 'Stereotypes and Prejudice: Their Automatic and Controlled Components' Journal of Personality and Social Psychology 56: 5-18.

Devine, P.G. and Monteith, M.J. (1999) 'Automaticity and Control Stereotyping', in S. Chaiken and Y. Trope (eds), Dual Process Theories Social Psychology. New York: Guilford Press, 339-60.

Dixon, D., Bottomley, A.K., Coleman, C.A., Gill, M. and Wall, D. (1989) 'Reality and Rules in the Construction and Regulation of Police Suspicion' International Journal of the Sociology of Law 17(3): 345-62.

Fitzgerald, M. (1999) Final Report into Stop and Search. London: Metropolitan Police Service.

Gergen, K. (1994) Realities and Relationships: Soundings in Social Construction. Cambridge, MA: Harvard University Press.

Gergen, K. and Gergen, M. (1988) 'Narrative and the Self as Relationship', in L. Berkowitz (ed.), Advances in Experimental Social Psychology, vol. 21. New York: Academic Press. 
Goodenough, O.R. (1997) 'Biology, Behaviour, and Criminal Law: Seeking a Responsible Approach to an Inevitable Interchange' Vermont Law Review 22: 263-94.

Goodenough, O.R. and Prehn, K. (2006) 'A Neuroscientific Approach to Normative Judgment in Law and Justice', in S. Zeki and O.R. Goodenough (eds), Law \& the Brain, 77-109. New York: Oxford University Press, 80.

Gruter, M. (1992) 'An Ethological Perspective on Law and Biology', in R.D. Masters and M. Gruter (eds), The Sense of Justice: Biological Foundations of Law. Newbury Park, CA: Sage, 95-105.

Hart, H.L.A. (1961) The Concept of Law. Oxford: Clarendon.

Holmes, O.W. (1881) The Common Law. Boston, MA: Little, Brown \& Co.

Home Office (2005) Code of Practice for the Exercise by Police Officers of Statutory Powers of Stop and Search, Code A. London: Home Office.

Home Office (2005) Stop and Search Manual. London: Home Office.

Howard, C., Tuffin, K. and Stephens, C. (2000) 'Unspeakable Emotion: A Discursive Analysis of Police Talk about Reactions to Trauma' Journal of Language and Social Psychology 19(3): 295-314.

Jordan, P. (2000) Stop and Search: Impact of Crime on Public Opinion. London: Police Foundation.

Kelson, H. (1934) Reine Rechtslehre, einleitung in die rechtswissenshaftliche problematic, Leipzig, trans. F. Deuticke (1992), Introduction to the Problems of Legal Theory. Oxford: Clarendon.

Kleinig, J. (1996) The Ethics of Policing. Cambridge: Cambridge University Press.

Kohlberg, L. (1969) 'Stage and Sequence: The CognitiveDevelopmental Approach to Socialisation', in D.A. Goslin (ed.), Handbook of Socialization Theory and Research. Chicago, IL: Rand McNally, 347-480.

Lerner, C. (2006) 'Reasonable Suspicion and Mere Hunches' Vanderbilt Law Review 59 (2): 405-73.

Lippmann, W. (1965 [1922]) Public Opinion. London: The Free Press/ Collier Macmillan.

McAra, L. and McVie, S. (2005) "The Usual Suspects"? Street-life, Young Offenders and the Police' Criminal Justice 5(1): 5-35.

Macpherson, W. (1999) The Stephen Lawrence Inquiry, Cm 4262-I.

McConville, M., Sanders, A. and Leng, R. (1991) The Case for the Prosecution. London: Routledge.

Macrae, C.N., Milne, A.B. and Bodenhausen, G.V. (1994) 'Stereotypes as Energy-Saving Devices: A Peek inside the Cognitive Toolbox' Journal of Personality and Social Psychology 66: 37-47.

Maguire, M., Morgan, R. and Reiner, R. (2007) The Oxford Handbook of Criminology. Oxford: Oxford University Press.

Ministry of Justice (2009) Statistics on Race and the Criminal Justice System 2007/8. A Ministry of Justice publication under Section 95 of the Criminal Justice Act 1991. London: Ministry of Justice. 
Nelson, T.E., Acker, M. and Manis, M. (1996) 'Irrepressible Stereotypes' Journal of Experimental Social Psychology 32: 13-38.

Neuberg, S.L. (1989) 'The Goal of Forming Accurate Impressions during Social Interactions: Attenuating the Impact of Negative Expectancies' Journal of Personality and Social Psychology 56: 374-86.

Perdue, C. and Gurtman, M. (1990) 'Evidence for the Automaticity of Ageism' Journal of Experimental Social Psychology 26: 199-216.

Piaget, J. (1965) The Moral Judgment of the Child. New York: Free Press.

Pickering, M. (1995) 'The Politics and Psychology of Stereotyping' Media, Culture, and Society 17: 691-700.

Pickering, M. (2001) Stereotyping: The Politics of Representation. London: Palgrave.

Quinton, P., Bland, N. and Miller, J. (2000) Police Stops, DecisionMaking and Practice. London: Home Office, Policing and Reducing Crime Unit.

Qureshi, F. and Farrell, G. (2006) 'Stop and Search in 2004: A Survey of Police Officer Views and Experiences' International Journal of Police Science \& Management 8(2): 83-103.

Reid, K. (2009) 'Race Issues and Stop and Search: Looking behind the Statistics' The Journal of Criminal Law 73(2): 165-83.

Sanders, A. and Young, R. (2007) 'From Suspect to Trial', in M. Maguire, R. Morgan and R. Reiner (eds), The Oxford Handbook of Criminology. Oxford: Oxford University Press.

Scarman, L. (1981) Report on the Brixton Disorders of 10-12 April 1981, Cmnd 8427. London: HMSO.

Solas, J. (1992) 'Ideological Dimensions Implicit in Kelly's Theory of Personal Constructs' International Journal of Personal Construct Psychology 5: 377-91.

Tranel, D. and Damasio, H. (1991) 'Somatic Markers and the Guidance of Behaviour: Theory and Preliminary Testing', in H.S. Levin, H.M. Eisenberg and A.L. Benton (eds), Frontal Lobe Function and Dysfunction. New York: Oxford University Press.

Waddington, P.A., Stenson, K. and Don, D. (2004) 'In Proportion: Race, and Police Stop and Search' British Journal of Criminology 44: 889-914.

Walker, C. and Starmer, K. (1993) Justice in Error. Blackstone: London.

Walker, S. (1993) Taming the System: The Control of Discretion in Criminal Justice 1959-1990. Oxford: Oxford University Press.

Wegener, D.T., Clark, J.K., and Petty, R.E. (2006) 'Not All Stereotyping Is Created Equally: Differential Consequences between Thoughtful versus Nonthoughtful Stereotyping' Journal of Personality and Social Psychology 90 (1): 42-59.

Weinreb, L.L. (1987) Natural Law and Justice. Cambridge, MA: Harvard University Press. 
Willis, C. (1983) The Use and Effectiveness and Impact of Police Stop and Search Powers. London: Home Office.

Zawadzki, B. (1942) 'Limitations of the Scapegoat Theory of Prejudice' Journal of Abnormal and Social Psychology 43: 127-41, 140. 